\title{
Enhancement of Drought Tolerance in Trifoliate Orange by Mycorrhiza: Changes in Root Sucrose and Proline Metabolisms
}

\author{
Fei ZHANG ${ }^{1,2}$, Jia-Dong $\mathrm{HE}^{1,2}$, Qiu-Dan $\mathrm{NI}^{1,2}$, Qiang-Sheng WU ${ }^{1,2,3}$, \\ Ying-Ning $\mathrm{ZOU}^{1,2 *}$ \\ ${ }^{1}$ College of Horticulture and Gardening, Yangtze University, Jingzhou, 434025 Hubei, China; 18995851618@163.com; \\ hejiadong1994@163.com;936948253@qq.com;wuqiangsh@163.com; zouyingning@163.com(*corresponding author) \\ ${ }^{2}$ Institute of Root Biology, Yangtze University, Jingzhou, 434025 Hubei, China \\ ${ }^{3}$ University of Hradec Kralove, Faculty of Science, Department of Chemistry, 50003 Hradec Kralove, Czech Republic; wuqiangsh@163.com
}

\begin{abstract}
Sucrose and proline metabolisms are often associated with drought tolerance of plants. This study was conducted to investigate the effects of two arbuscular mycorrhizal fungi (AMF) species (Funneliformis mosseae and Paraglomus occultum) on root biomass, lateral root number, root sucrose and proline metabolisms in trifoliate orange (Poncirus trifoliata) seedlings under well-watered (WW) or drought stress (DS). All the AMF treatments significantly increased root dry weight, taproot length, and the number of lateral roots in $1^{\text {st }}, 2^{\text {nd }}$, and $3^{\text {rd }}$ class under WW and DS. Mycorrhizal seedlings conferred considerably higher fructose and glucose concentrations but lower sucrose accumulation, regardless of soil water status. Under DS, F. mosseae treatment significantly increased root sucrose synthase (SS, degradative direction) and sucrose phosphate synthase (SPS) activity but deceased root acid invertase (AI) and neutral invertase (NI) activity, and P. occultum inoculation markedly increased root AI, NI, SS, and SPS activities. AMF treatments led to a lower proline accumulation in roots, in company with lower activities of $\Delta^{1}$-pyrroline-5-carboxylate synthetase (P5CS), $\delta$-ornithine aminotransferase (OAT), $\Delta^{1}$ pyrroline-5-carboxylate reductase ( $\mathrm{P} 5 \mathrm{CR}$ ), and proline dehydrogenase (ProDH) in roots. It appears that the AM symbiosis induced greater root development and sucrose and proline metabolisms to adapt DS.
\end{abstract}

Keywords: arbuscular mycorrhizal fungi, citrus, invertase, osmotic adjustment, sugar

\section{Introduction}

Arbuscular mycorrhizal fungi (AMF), a kind of beneficial soil microorganism, can form mycorrhizal association with $\sim 80 \%$ of land's plant species. Mycorrhizal symbiosis can help the host plant to absorb water and mineral nutrients from the soil to the fungal partner, and AMF get as many as $20 \%$ of photosynthetic carbon of the host plant (Parniske, 2008). Such AM symbiosis is a key component in resisting drought stress in various economic crops, including pepper (Davies, 2002), macadamia (Yooyongwech et al., 2013), citrus (Huang et al., 2014), and so on. The underlying mechanisms of mycorrhizal plants in enhancing drought tolerance have not yet been clearly elucidated. Possible mechanisms include (i) water and nutrient uptake directly by external hyphae (Zou et al., 2015), (ii) optimizing the root system architecture (Liu et al., 2016), (iii) greater osmotic adjustment capacity (Wu et al., 2007), (iv) enhancement of antioxidant defense systems (Huang et al., 2014), and (v) soil structure improvement by glomalin (Wu et al., 2008).

Drought stress (DS) invariably limits plant growth performance and yield to a series of irrigated plants including citrus (Abbaspour et al., 2012; Wu et al., 2013a). Under DS conditions, osmotic adjustment (OA) starts for the sake of inducing water potential of plants to maintain an optimal gradient for water flow from soils into roots. Sugars and proline as osmoprotectants, play key roles in accelerating water absorption and keeping the macromolecular structure and the sub cellular membrane under DS (Gomes et al., 2010). Studies showed that mycorrhizal plants exhibited higher sugar concentrations (Wu et al., 2007; Talaat and Shawky, 2014) due to mycorrhizal carbon cools for the fungal development in terms of sucrose cleavages (Franken, 2010) and AMinduced hydrolysis of starch to sugars in metabolic processes (Boldt et al., 2011). Moreover, accumulation of sugars in 
mycorrhizal plants would maintain both the membrane integrity and the osmoprotectant balance in plant cell under DS (Kapoor et al., 2013). Prior to absorption and utilization by AMs, sucrose in roots must be cleaved into hexoses via either invertases or sucrose synthase (SS) (Schubert et al., 2003). In general, sucrose invertases include acid invertase (AI) and neutral invertase (NI). Earlier studies showed that AMs notably decreased the activity of $\mathrm{AI}$ and NI in roots (Wu et al., 2015). In addition, sucrose phosphate synthase (SPS), a kind of soluble enzyme observed in the cytoplasm, has the synergy with sucrose invertase in mediating long-distance transportation and metabolism in tissue sink of carbon in plants (Zhang and $\mathrm{Li}$, 2002). Likewise, SS as a reversible type of glycosyl transferase existed in the cytoplasm that plays a key role in keeping the equilibrium between sugar metabolism and sink strength (Schäfer et al., 2005).

Proline is a compatible solute participating in $\mathrm{OA}$ in plants exposed to DS (Hassine et al., 2008). Proline is synthesized not only by the glutamate synthetic pathway with $\Delta^{1}$-pyrroline-5-carboxylate synthetase (P5CS) in cytoplasm or chloroplast but also by ornithine synthetic pathway with $\delta$-ornithine aminotransferase (OAT) in mitochondria (Ashraf and Foolad, 2007; Szabados and Savoure, 2009). Proline dehydrogenase (ProDH) generally induces proline transformed into $\Delta^{1}$-pyrroline-5carboxylate (P5C) (Kiyosue et al., 1996), while P5C can be processed by P5C reductase (P5CR) into proline ( $\mathrm{Hu}$ et al., 1992). Studies showed that plants inoculated with AMF had a lower or higher level of proline than non-mycorrhizal counterparts under DS conditions (Wu et al., 2007; Abbaspour et al., 2012; Asrar et al., 2012; Zou et al., 2013).

Trifoliate orange [Poncirus trifoliata (L.) Raf.], one of citrus rootstocks used in China, India and Japan, is strongly dependent on AMF in fields, due to less or no root hairs. Earlier studies have shown the positive effect of AMF on drought tolerance of trifoliate orange (Wu et al., 2007, 2013a, 2015; Huang et al., 2014), but information regarding sucrose and proline metabolisms are poorly known under DS. The objective of the present work was to clarify the effect of two AM fungal species (Funneliformis mosseae and Paraglomus occultum) on sucrose and proline metabolism of trifoliate orange seedlings under DS conditions.

\section{Materials and Methods}

\section{Plant culture}

Seeds of trifoliate orange were surface sterilized with $70 \%$ of ethanol for $15 \mathrm{~min}$ and then germinated in autoclaved $\left(0.11 \mathrm{MPa}, 121{ }^{\circ} \mathrm{C}, 2 \mathrm{~h}\right)$ sands in a growth chamber $\left(28 / 20^{\circ} \mathrm{C}\right.$ day/night temperature, 1200 $\mu \mathrm{mol} / \mathrm{m}^{2} / \mathrm{s}$ photon flux density, and $80 \%$ relative humidity). After three weeks, two four-leaf-old seedlings with uniform size were transplanted into a 1.18-L plastic pot, each filled with $3.0 \mathrm{~kg}$ autoclaved $\left(0.11 \mathrm{MPa}, 121^{\circ} \mathrm{C}, 2 \mathrm{~h}\right)$ substrates of soils and sands $(4: 1, \mathrm{v} / \mathrm{v})$.

Funneliformis mosseae (Nicol. \& Gerd.) Schüßler \& Walker and Paraglomus occultum (Walker) Morton \& Redecker were used here, based on the research of Wu et al.
(2015). The mycorrhizal inoculums were propagated through an identified spore with a host plant white clover (Trifolium repens) for 16 weeks under potted conditions. The inoculum consisted of AM-infected root segments, spores, extraradical hyphae and sands. The dosage of 1000 spores was mixed with the growth substance of the pot at the time of plant transplanting. Non-AMF treated pot received the same amount of antoclaved $\left(0.11 \mathrm{MPa}, 121^{\circ} \mathrm{C}\right.$, $2 \mathrm{~h}$ ) mycorrhizal inocula, and $3 \mathrm{~mL}$ inoculums filtrate ( 25 $\mu \mathrm{m}$ filter) was added into the non-AMF pot for other microbial communities. The pots were placed in a glass house with a photo flux density of $728-965 \mu \mathrm{mol} / \mathrm{m}^{2} / \mathrm{s}, 20$ $35 / 15-26^{\circ} \mathrm{C}$ (day/night) and a relative humidity of $70-95 \%$ from March 25 to August 30, 2013.

\section{Experimental design}

The experiment consisted of a randomized block design with three mycorrhizal inoculations (with $F$. mosseae, $P$. occultum and -AMF) and two water treatments (wellwatered, WW, $75 \%$ of maximum water holding capacity of soils; DS, $55 \%$ of maximum water holding capacity of soils). Each treatment had five replicates, leading to a total of 30 pots.

Before DS was begun, soil water of all these pots was kept in WW for 87 days. Subsequently, half of the seedlings were exposed to DS status for 71 days, and the other seedlings were still subject to WW status for 71 days. During water treatment periods, soil water status of the pot was determined daily through weighing and the quantity of water loss was re-supplied to keep the target soil water status at 6:00 PM. Meanwhile, $20 \mathrm{~mL}$ distilled water was weekly replaced with $20 \mathrm{~mL}$ Hoagland solutions for nutrients support.

\section{Variable determinations}

After 71 days of DS treatment, AM and non-AM seedlings were harvested. Roots of two seedlings from each replicate were collected as a sample. The taproot length was measured, and subsequently the number of different order lateral roots was counted. Dry weight of roots was determined after $75^{\circ} \mathrm{C}$ for $48 \mathrm{~h}$.

Fresh fine root segments $(1 \mathrm{~cm}$ long) were cleared with $10 \%(\mathrm{w} / \mathrm{v}) \mathrm{KOH}$ and stained with $0.05 \%(\mathrm{w} / \mathrm{v})$ trypan blue by the protocol outlined by Phillips and Hayman (1970). Root mycorrhizal colonization was the percentage of AMFcolonized root length against total observed root length.

Root proline concentration $(\mathrm{mg} / \mathrm{g} \mathrm{FW})$ was determined by the acid-ninhydrine method described by Bates et al. (1973). Root P5CS and ProDH activity was assayed according to Zou et al. (2013). One unit of P5CS was expressed as the enzyme amount of $1.0 \mu \mathrm{mol}$ glutamate during $1 \mathrm{~min}$ from $1 \mathrm{~g}$ root $(\mathrm{U} / \mathrm{g} \mathrm{FW})$, and one unit of ProDH activity was expressed as the absorbance of an increase of 0.01 at $600 \mathrm{~nm}$ in $1 \mathrm{~min}(\mathrm{U} / \mathrm{g} \mathrm{FW})$. Determination of root OAT activity was accorded to Kim et al. (1994), and OAT activity was defined as the amount of $1 \mathrm{nmol}$ P5C during $1 \mathrm{~min}$ for $1 \mathrm{~g}$ fresh sample (U/g FW). Activity of root P5CR was assayed by the protocol of Chilson (1991), and one unit of P5CR activity was expressed as the enzyme amount of $1.0 \mu \mathrm{mol} \mathrm{NADH}$ during $1 \mathrm{~min}$ at $25^{\circ} \mathrm{C}(\mathrm{U} / \mathrm{g} \mathrm{FW})$. 
272

Root sucrose, glucose and fructose concentration was determined according to the method of Wu et al. (2015). Activity of AI and NI in roots was assayed according to the protocol of $\mathrm{Wu}$ et al. (2013b). The activity of SS (degradative direction) and SPS was measured according to Lowell et al. (1989) and Hubbard et al. (1989), respectively.

\section{Statistical analysis}

Data (means $\pm \mathrm{SD}, n=5$ ) were analyzed with twofactor variance (ANOVA) in SAS software (SAS Institute Inc., Cary, NC, USA), and the Duncan's multiple range test $(P<0.05)$ was used to compare significant differences between treatments.

\section{Results}

\section{Mycorrbizal colonization and root performance}

DS treatment significantly reduced root colonization by $41 \%$ under $F$. mosseae conditions and by $30 \%$ under $P$. occultum conditions, respectively, as compared with WW treatment (Table 1). In addition, $P$. occultum-inoculation showed considerably greater root AMF colonization than $F$. mosseae-inoculation, regardless of WW or DS.
In general, AM seedlings represented significantly higher root biomass, taproot length and the number of lateral roots in the $1^{\text {st }}, 2^{\text {nd }}$, and $3^{\text {ta }}$ class than non-AM controls, irrespective of soil water status (Table 1). Meanwhile, treatment with $P$. occultum exhibited a relatively greater effect on these root variables than $F$. mosseae under WW and DS conditions.

\section{Root fructose, glucose and sucrose concentrations}

AMF colonization substantially increased root glucose concentrations than non-AMF treatment, regardless of soil water status and AMF species (Fig. 1b). Root sucrose concentrations were notably higher under non-AMF condition than under $F$. mosseae and $P$. occultum conditions, regardless of WW or DS, except a nonsignificant difference between non-AMF and $F$. mosseae under WW (Fig. 1c). AM seedlings represented markedly higher root fructose concentrations than non-AM seedlings, irrespective of soil water status and AMF species (Fig. 1a). There was a significant interacted effect of AMF and DS on root glucose and sucrose concentrations (Table 2).

Table 1. Mycorrhizal colonization, root dry weight, taproot length and number of lateral roots of Funneliformis mosseae- and Paraglomus occultumcolonized trifoliate orange (Poncirus trifoliata) seedlings grown under well-watered (WW) and drought stress (DS) conditions

\begin{tabular}{|c|c|c|c|c|c|c|c|}
\hline \multirow{2}{*}{ Water status } & \multirow{2}{*}{ AMF status } & \multirow{2}{*}{$\begin{array}{c}\text { Root AMF } \\
\text { colonization (\%) }\end{array}$} & \multirow{2}{*}{$\begin{array}{l}\text { Root dry weight } \\
\text { (g DW/plant) }\end{array}$} & \multirow{2}{*}{$\begin{array}{c}\text { Taproot } \\
\text { length }(\mathrm{cm})\end{array}$} & \multicolumn{3}{|c|}{ Number of lateral roots (\#/plant) } \\
\hline & & & & & $1^{\mathrm{st}}$ & $2^{\text {nd }}$ & $3^{\text {rd }}$ \\
\hline \multirow{3}{*}{ WW } & F.mosseae & $57.54 \pm 5.53 b$ & $0.93 \pm 0.07 \mathrm{~b}$ & $42.0 \pm 1.9 \mathrm{a}$ & $76 \pm 4 a$ & $156 \pm 6 b$ & $27 \pm 3 b$ \\
\hline & P. occultum & $70.53 \pm 5.60 \mathrm{a}$ & $1.37 \pm 0.11 \mathrm{a}$ & $40.6 \pm 1.8 \mathrm{a}$ & $78 \pm 1 \mathrm{a}$ & $210 \pm 5 a$ & $70 \pm 3 a$ \\
\hline & $-\mathrm{AMF}$ & $0 \pm 0 \mathrm{e}$ & $0.63 \pm 0.03 \mathrm{~d}$ & $35.9 \pm 1.4 b$ & $63 \pm 3 b c$ & $105 \pm 6 c$ & $9 \pm 2 d$ \\
\hline \multirow{3}{*}{ DS } & F.mosseae & $34.19 \pm 2.98 \mathrm{~d}$ & $0.65 \pm 0.10 \mathrm{~cd}$ & $33.9 \pm 1.4 b$ & $61 \pm 4 c$ & $91 \pm 3 d$ & $21 \pm 4 c$ \\
\hline & P. occultum & $49.71 \pm 5.11 \mathrm{c}$ & $0.75 \pm 0.05 c$ & $35.2 \pm 2.0 \mathrm{~b}$ & $67 \pm 3 b$ & $108 \pm 8 c$ & $28 \pm 3 b$ \\
\hline & -AMF & $0 \pm 0 \mathrm{e}$ & $0.52 \pm 0.04 \mathrm{e}$ & $30.4 \pm 1.5 \mathrm{c}$ & $55 \pm 3 d$ & $79 \pm 3 e$ & $6 \pm 2 d$ \\
\hline \multicolumn{8}{|l|}{ Signification } \\
\hline DS & & $* *$ & ** & ** & ** & ** & ** \\
\hline AMF & & $* *$ & ** & ** & ** & ** & ** \\
\hline $\mathrm{DS} \times \mathrm{AMF}$ & & NS & ** & NS & NS & ** & ** \\
\hline
\end{tabular}

Note: Data (means $\pm \mathrm{SD}, n=5)$ followed by different letters between treatments indicated significant differences at $5 \%$ level. NS: not significant. ${ }^{*} \mathrm{P}<0.05 ;{ }^{* *} \mathrm{P}<0.01$

Table 2. Significance of variable variations between AM and non-AM colonized trifoliate orange (Poncirus trifoliata) seedlings under well-watered (WW) and drought stress (DS) conditions

\begin{tabular}{|c|c|c|c|}
\hline Variables & AMF & Drought stress (DS) & $\mathrm{AMF} \times \mathrm{DS}$ \\
\hline Root glucose & ** & ** & ** \\
\hline Root sucrose & ** & ** & ** \\
\hline Root fructose & ** & ** & NS \\
\hline Root AI & ** & ** & ** \\
\hline Root NI & ** & ** & ** \\
\hline Root SS & ** & ** & ** \\
\hline Root SPS & ** & ** & * \\
\hline Root proline & ** & ** & ** \\
\hline Root P5CR & ** & ** & NS \\
\hline Root OAT & ** & ** & ** \\
\hline Root ProDH & ** & NS & ** \\
\hline Root P5CS & ** & ** & NS \\
\hline
\end{tabular}

Note: ${ }^{*} \mathrm{P}<0.05$; ${ }^{* *} \mathrm{P}<0.01$. Abbreviations: AI, acid invertase; AMF, arbuscular mycorrhizal fungus; NI, neutral invertase; NS, not significant; OAT, ornithine- $\delta$ aminotransferase; ProDH, proline dehydrogenase; P5CR, $\Delta^{1}$-pyrroline-5-carboxylate reductase; P5CS, $\Delta^{1}$-pyrroline-5-carboxylate synthetase; SPS, sucrose phosphate synthase; SS, sucrose synthase 


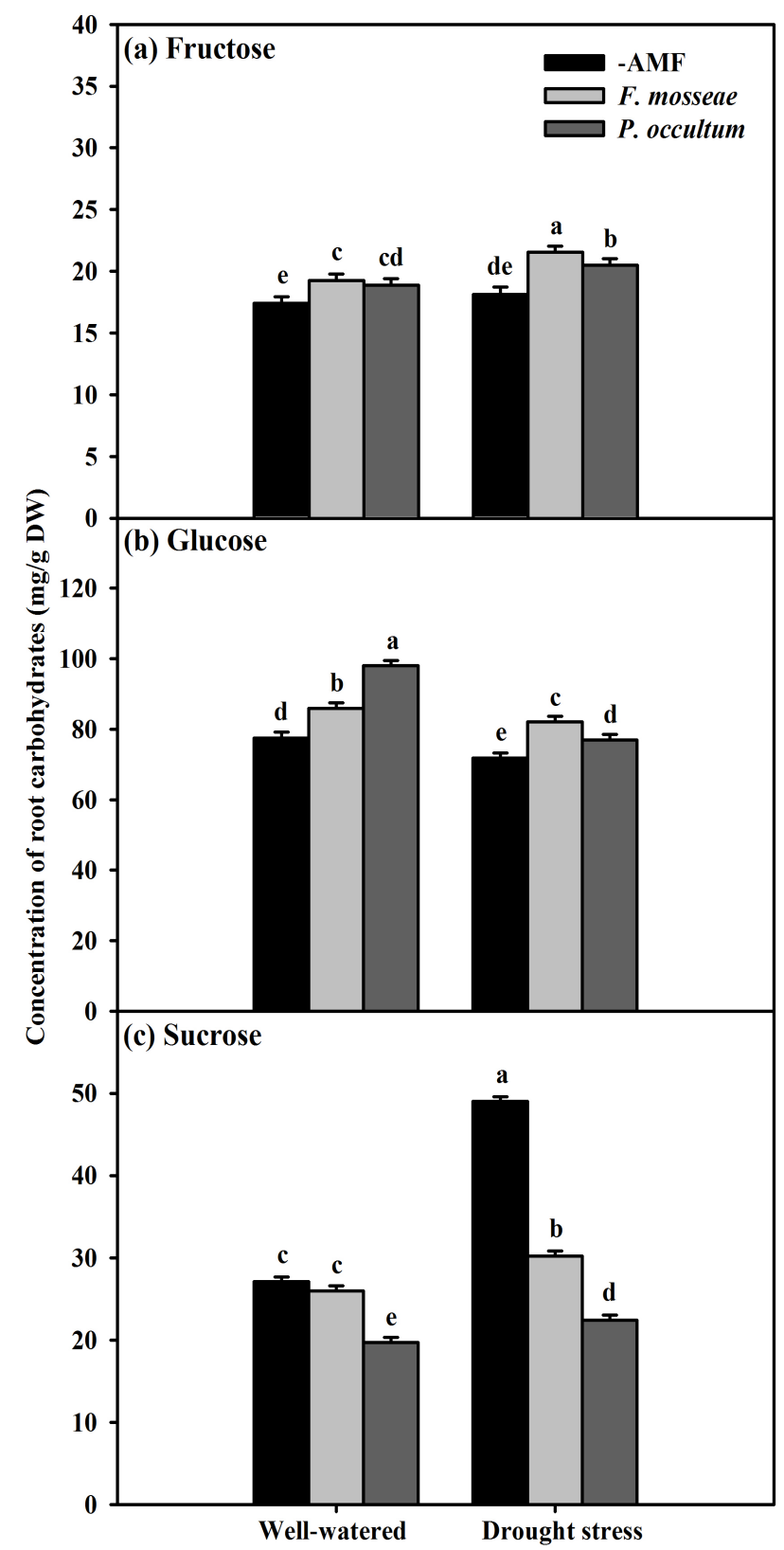

Fig. 1. Effects of Funneliformis mosseae and Paraglomus occultum on root fructose (a), glucose (b), and sucrose (c) concentrations of Poncirus trifoliata seedlings under wellwatered (WW) and drought stressed (DS) conditions. Data (means $\pm \mathrm{SD}, n=5$ ) followed by the same letter above the bars are not significantly different among treatments at $\mathrm{P}<0.05$

\section{Root sucrose-metabolized enzyme activities}

The seedlings inoculated with $F$. mosseae significantly increased the activity of AI, NI, and SPS in roots by $19 \%$, $52 \%$, and $70 \%$ under WW condition, compared to nonAMF-inoculated seedlings (Fig. 2a, 2b, 2d; Table 2). Under DS, $F$. mosseae inoculation also notably increased the activity of root SS and SPS by $117 \%$ and $82 \%$ (Fig. 2c, 2 d; Table 2), whereas F. mosseae markedly decreased the activity of root AI and NI by $37 \%$ and $37 \%$ (Fig. 2a, 2b; Table 2). Compared with non-AMF seedlings, $P$. occultuminoculated seedlings significantly increased the activity of root AI, NI, SS, and SPS by 38\%, 50\%, 210\%, and $19 \%$ under DS condition (Fig. 2a-2d; Table 2). Under WW conditions, $P$. occultum treatment significantly increased the root SPS activity by $23 \%$ but decreased the root AI, NI, and SS activity by $8 \%, 21 \%$, and $50 \%$, respectively.

\section{Root proline concentration}

Compared with non-AMF treatment, F. mosseae inoculation notably decreased the root proline concentration by $32 \%$ and $30 \%$, and $P$. occultum inoculation significantly reduced the root proline concentration by $32 \%$ and $13.33 \%$ under WW and DS, respectively (Fig. 3). There was a significant interaction in root proline concentration between AMF and DS treatment (Table 2).

\section{Root proline-metabolized enzyme activities}

Mycorrhizal seedlings showed considerably lower activities of root OAT, P5CR, ProDH, and P5CS than non-mycorrhizal seedlings: $60 \%, 52 \%, 53 \%$, and $30 \%$ lower under $F$. mosseae and $34 \%, 48 \%, 63 \%$, and $17 \%$ lower under P. occultum under WW; $18 \%, 46 \%, 72 \%$, and $28 \%$ lower under $F$. mosseae, and $1 \%, 41 \%, 32 \%$, and $28 \%$ under $P$. occultum under DS (Fig. 4a-4d). Root OAT and ProDH activity was markedly interactively affected by AMF and DS (Table 2).

\section{Discussion}

The 71-day DS treatment markedly decreased the root colonization of trifoliate orange plants by $F$. mosseae and $P$. occultum. This is in agreement with the reports of Huang et al. (2017), who found that trifoliate orange seedlings had significantly lower root AMF colonization under DS than under WW condition after inoculation with $F$. mosseae. Possibly, the negative effects of DS on root mycorrhizal colonization ascribe to the inhibition in both the germination of spores and the spread of soil hyphae (Huang et al., 2014; Zhang et al., 2014). Even so, such root mycorrhizal colonization still stimulated the enhancement of root biomass, taproot length, and the number of different order lateral roots under DS condition. The greater root biomass and morphology in AM seedlings would enlarge the contacted area of roots to soils, thus, potentially enhancing water and nutrient absorption under DS conditions (Remans et al., 2012; Wu et al., 2013a).

In this work, AMF treatment significantly increased root glucose and fructose concentrations while notably decreased root sucrose concentration under WW and DS, regardless of AMF species. The changes can be interpreted that in roots, AMs need hexoses, especially glucose, for its formation and development, which is originated from sucrose cleavage (Schubert et al., 2003).

The present study showed lower AI, NI and SS activities in roots of $P$. occultum-inoculated seedlings under WW condition, which was in agreement with previous works in trifoliate orange inoculated with five AMF species (Wu et al., 2015). Such reductions of sucrose-cleaved enzyme activities in mycorrhizal seedlings were due to the fact that sucrose was cleaved in phloem apoplasts unloading in roots, in order to maintain a suitable sucrose concentration 
274

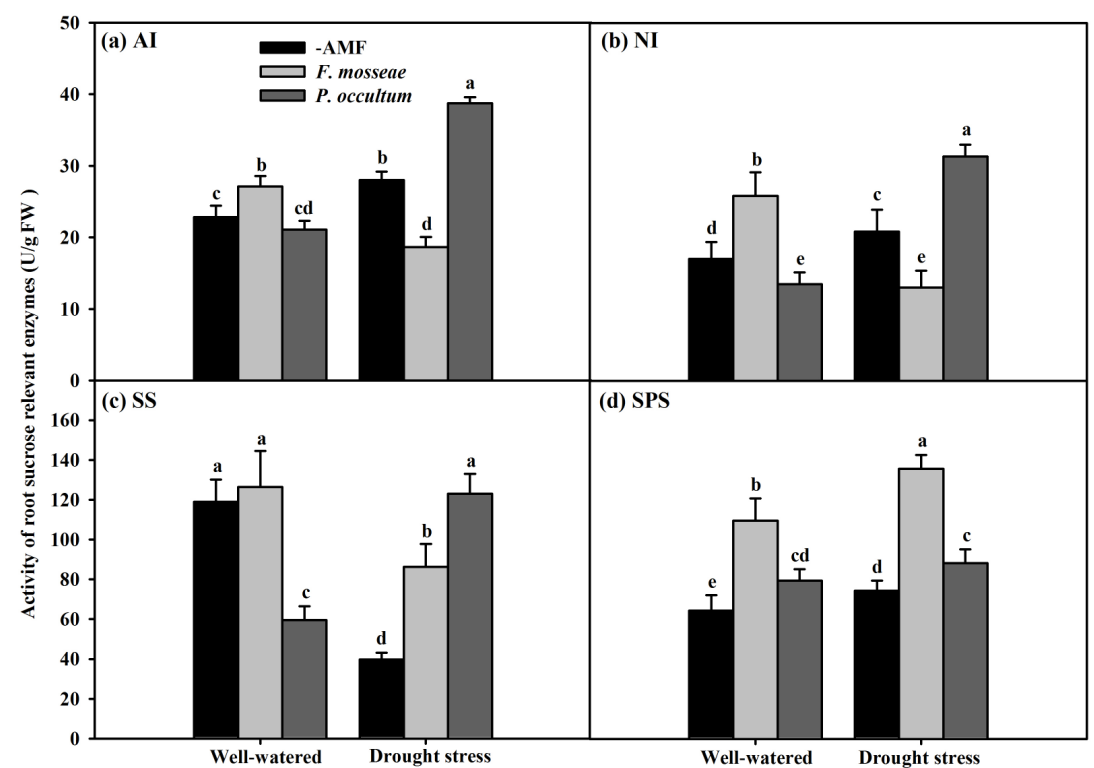

Fig. 2. Effects of Funneliformis mosseae and Paraglomus occultum on activities of acid invertase (AI) (a), neutral invertase (NI) (b), sucrose synthase (SS, degradative direction) (c), and sucrose phosphate synthase (SPS) (d) in roots of Poncirus trifoliata seedlings under well-watered (WW) and drought stressed (DS) conditions. Data (means \pm SD, $n=5$ ) followed by the same letter above the bars are not significantly different among treatments at $\mathrm{P}<0.05$

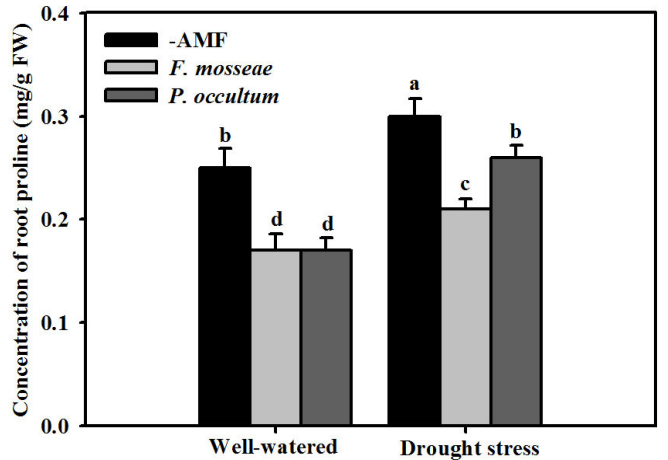

Fig. 3. Effects of Funneliformis mosseae and Paraglomus occultum on root proline concentration of Poncirus trifoliata seedlings under well-watered (WW) and drought stressed (DS) conditions. Data (means \pm SD, $n=5$ ) followed by the same letter above the bars are not significantly different among treatments at $\mathrm{P}<0.05$

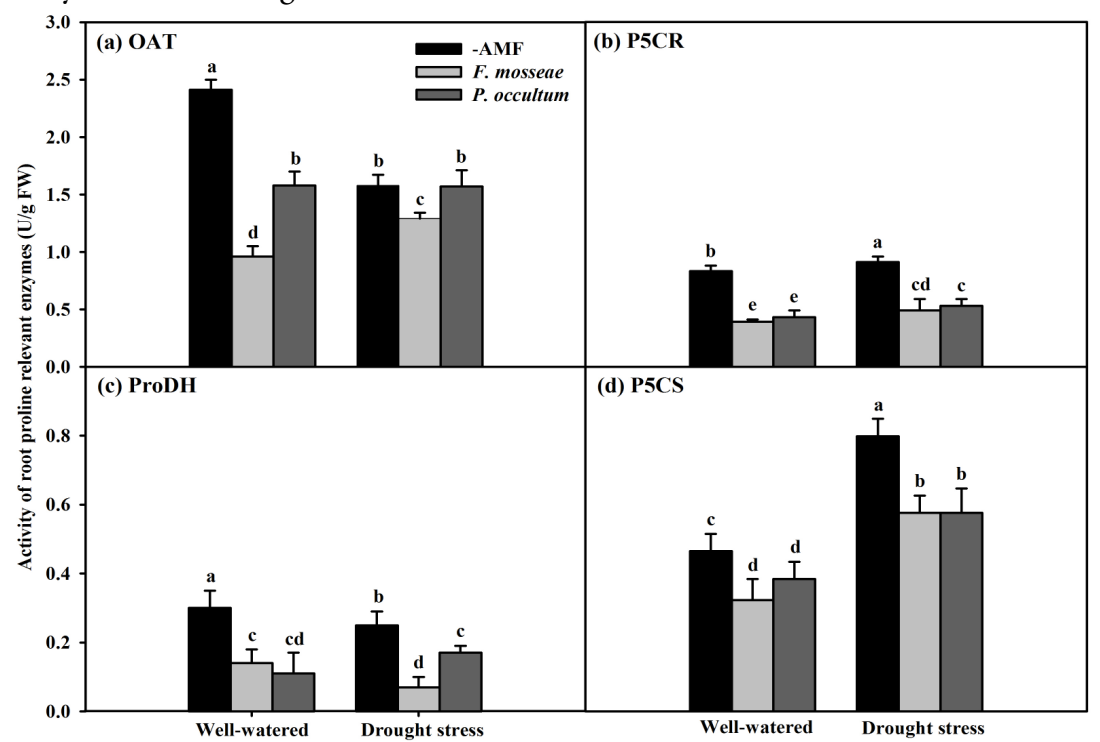

Fig. 4. Effects of Funneliformis mosseae and Paraglomus occultum on activities of ornithine- $\delta$-amino transferase (OAT) (a), $\Delta^{1}$ pyrroline-5-carboxylate reductase (P5CR) (b), proline dehydrogenase (ProDH) (c), and $\Delta^{1}$-pyrroline-5-carboxylate synthetase (P5CS) (d) in roots of Poncirus trifoliata seedlings under well-watered (WW) and drought stressed (DS) conditions. Data (means $\pm \mathrm{SD}, n=5$ ) followed by the same letter above the bars are not significantly different among treatments at $\mathrm{P}<0.05$ 
gradient between the source and the sink (Schaarschmidt $e t$ al., 2007). In contrast, the seedlings inoculated with $F$. mosseae revealed higher root $\mathrm{AI}$ and $\mathrm{NI}$ activities relative to non-AM seedlings under WW condition, suggesting that the responses of root $\mathrm{AI}$ and $\mathrm{NI}$ activities to mycorrhization are mycorrhizal fungal dependent (Wu et al., 2015). The present study also showed that root SS (degradative direction) and SPS activities were significantly increased by AMF inoculation under WW and DS conditions, except the similar SS level between non-AMF and $F$. mosseae and a lower SS level between non-AMF and $P$. occultum under WW. These results indicated that mycorrhization induced a higher root SPS activity to synthesize sucrose and also modulated diverse changes in sucrose-cleaved enzymes for greater hexose concentration in roots, which is beneficial for OA.

The present work showed that root proline concentration was significantly lower in AMF-treated trifoliate orange seedlings than in non-AMF colonized seedlings under WW and DS conditions, which is independent on AMF species. Similar results were found in Macadamia tetraphylla plants (Yooyongwech et al., 2013). The lower proline accumulation under mycorrhization suggests less damage to AM seedlings exposed to DS conditions, resulting in a successful avoidance of DS in AM plants (Subramanian and Charest, 1995; Wu et al., 2007; Zou et al., 2013).

On the other hand, the significantly lower activity of P5CS, P5CR and OAT in roots was found in the AM seedlings than in non-AM plants under WW and DS conditions, except the similar root OAT activity between non-AMF and $P$. occultum under DS. The similar result was also reported by Zou et al. (2013). It is concluded that the lower proline accumulation under mycorrhization may be due to the inhibition of AMF-mediated glutamate and ornithine synthetic pathways (Szabados and Savoure, 2009). In addition, a significantly lower activity of root P5CR and ProDH was exhibited in mycorrhizal trifoliate orange plants under WW as well as DS conditions than nonmycorrhizal plants. It is well known that proline catabolism is another factor involved in the net proline accumulation under DS. $\Delta^{1}$-pyrroline-5-carboxylate (P5C) is transformed into proline by P5CR, and in return proline is catabolised by ProDH into P5C (Szabados and Savoure, 2009). The activity of root ProDH was decreased by AMs in this work, in company with a decrease of root P5CR, suggesting that P5CR may work together with ProDH in regulation of proline accumulation. In a word, AMs made the trifoliate orange root exhibiting greater functions in proline degradation than in proline accumulation, no matter plants were grown under DS or not.

\section{Conclusions}

Inoculation with $F$. mosseae and $P$. occultum considerably increased root biomass and lateral root formation under either WW or DS condition. Mycorrhizas induced greater hexose accumulation and lower sucrose accumulation in roots, which is closely related to the change in sucrose-cleaved enzyme activities. Mycorrhizal plants represented lower root proline accumulation, which was significantly positively correlated with root P5CS, OAT, P5CR and ProDH activity.

\section{Acknowledgements}

This study was supported by the Key Project of the Science and Technology Research, Hubei Provincial Department of Education (D20171304) and the Plan in Scientific and Technological Innovation Team of Outstanding Young, Hubei Provincial Department of Education (T201604).

\section{References}

Abbaspour H, Saeidi-Sarb S, Afshari H, Abdel-Wahhab MA (2012). Tolerance of mycorrhiza infected Pistachio (Pistacia vera $\mathrm{L}$.) seedling to drought stress under glasshouse conditions. Journal of Plant Physiology 169:704709.

Ashraf M, Foolad MR (2007). Roles of gycine betaine and proline in improving plant abiotic stress resistance. Environmental and Experimental Botany 59:206-216.

Asrar AA, Abdel-Fattah GM, Elhindi KM (2012). Improving growth, flower yield, and water relations of snapdragon (Antirbinum majus L.) plants grown under well-watered and water-stress conditions using arbuscular mycorrhizal fungi. Photosynthetica 50:305-316.

Bates LS, Waldren RP, Teare ID (1973). Rapid determination of free prolinefor water stress studies. Plant and Soil 39:205-207.

Boldt K, Pörs Y, Haupt B, Bitterlich M, Kühn C, Grimm B, Franken P (2011). Photochemical processes, carbon assimilation and RNA accumulation of sucrose transporter genes in tomato arbuscular mycorrhiza. Journal of Plant Physiology 168:1256-1263.

Chilson OP, Kelly-Chilson AE, Sieqei NR (1991). Pyrroline-5-carboxylate reductase in soybean nodules: isolation/partial primary structure/evidence for isozymes. Archives of Biochemistry and Biophysics 288:350-357.

Davies FT, Olalde-Portugal V, Aguilera-Gomez L, Alvarado MJ, FerrerCerrato RC, Boutton TW (2002). Alleviation of drought stress of Chile ancho pepper (Capsicum annuum L.cv.San Luis) with arbuscular mycorrgiza indigenous to Mexico. Scientia Horticulturae 92:347-359.

Franken $\mathrm{P}$ (2010). Molecular-physiological aspects of the AM symbiosis post penetration. In: Koltai H, Kapulnik Y (Eds). Arbuscular Mycorrhizas: Physiology and Function.Springer,New York pp 93-116.

Gomes FP, Oliva MA, Mielke MS, Almeida AAF, Aquino LA (2010). Osmotic adjustment, proline accumulation and cell membrane stability in leaves of Cocos nucifera submitted to drought stress. Scientia Horticulturae 126:379-384.

Hassine AB, Ghanem ME, Bouzid S, Lutts S (2008). An inland and a coastal population of the Mediterranean xero-halophyte species Atriplex balimus $\mathrm{L}$. differ in their ability to accumulate proline and gycinebetaine in response to salinity and water stress. Journal of Experimental Botany 59:1315-1326.

Hu CA, Delaunew AJ, Verma DP (1992). A bifunctional enzyme ( $\Delta^{1-}$ pyrroline-5-carboxylate synthetase) catalyzes the first two steps in proline biosynthesis in plants. Proceedings of the National Academy of Science 89:93549358.

Huang YM, Srivastava AK, Zou YN, Ni QD, Han Y, Wu QS (2014). Mycorrhizal-induced calmodulin mediated changes in antioxidant enzymes and growth response of drought-stressed trifoliate orange. Frontiers in Microbiology 5:682. 
276

Huang YM, Zou YN, Wu QS (2017). Alleviation of drought stress by mycorrhizas is related to increased root $\mathrm{H}_{2} \mathrm{O}_{2}$ efflux in trifoliate orange. Scientific Reports 7:42335.

Hubbard NL, Huber SC, Pharr DM (1989). Sucrose phosphate synthase and acid invertase as determinants of sucrose concentration in developing muskmelon (Cucumis melo L.) fruits. Plant Physiology 91:1527-1534.

Kapoor R, Evelin H, Mathur P, Giri B (2013). Arbuscular mycorrhiza: Approaches for abiotic stress tolerance in crop plants for sustainable agriculture. In: Tuteja N, Gill SS (Eds). Plant Acclimation to Environmental Stress. Springer,LLC pp 359-401.

Kim HR, Rho HW, ParkJW, Park BH, KimJS, Lee MW (1994). Assay of ornithine aminotransferase with ninhydrin. Analytical Biochemistry 223:205-207.

Kiyosue T, Yoshiba Y, Yamaguchi SK, Shinozaki K (1996). A nuclear gene encoding mitochondrial proline dehydrogenase, an enzyme involved in proline metabolism, is upregulated by proline but downregulated by dehydration in Arabidopsis. Plant Cell 8:1323-1335.

Liu J, Guo C, Chen ZL, He JD, Zou YN (2016). Mycorrhizal inoculation modulates root morphology and root phytohormone responses in trifoliate orange under drought stress. Emirates Journal of Food and Agriculture 28:251-256.

Lowell CA, Tomlinson PT, Koch KE (1989). Sucrose-metabolizing enzymes in transport tissue and adjacent sink structures in developing citrus fruit. Plant Physiology 90:1394-1402.

Parniske M (2008). Arbuscular mycorrhiza: the mother of plant root endosymbioses. Nature Reviews Microbiology 6:763-775.

Phillips JM, Hayman DS (1970). Improved procedures for clearing roots and staining parasitic and vesicular-arbuscular mycorrhizal fungi for rapid assessment of infection. Transaction of the British Mycological Society 55:158-163.

Remans T, Thijs S, Truyens S, Weyens N, Schellingen K, Keunen E, Gielen H, Cuypers A, Vangronsveld J (2012). Understanding the development of roots exposed to contaminants and the potential of plant-associated bacterial for optimization of growth. Annals Botany 110:239-252.

Schaarschmidt S, Gonzalez MZ, Roitsch T, Strack D, Sonnewald U, Hause B (2007). Regulation of arbuscular mycorrhization by carbon. The symbiotic interaction cannot be improved by increased carbon availability accomplished by root-specifically enhanced invertase activity. Plant Physiology 143:1827-1840.

Schäfer WE, Rohwer JM, Botha FC (2005). Partial purification and characterization of sucrose synthase in sugarcane. Journal of Plant Physiology 162:11-20.

Schubert A, Allara P, Morte A (2003). Cleavage of sucrose in roots of soybean (Glycine max) colonized by an arbuscular mycorrhizal fungus. New Phytologist 161:495-501.
Subramanian KS, Charest C (1995). Influence of arbuscular mycorrhizae on the metabolism of maize under drought stress. Mycorrhiza 5:273-278.

Szabados L, Savoure A (2009). Proline: a multifunctional amino acid. Trends in Plant Science 15:89-97.

Talaat NB, Shawky BT (2014). Protective effects of arbuscular mycorrhizal fungi on wheat (Triticum aestivum L.) Plants exposed to salinity. Environmental and Experimental Botany 98:20-31.

Wu QS, Lou YG, Li Y (2015). Plant growth and tissue sucrose metabolism in the system of trifoliate orange and arbuscular mycorrgizal fungi. Scientia Horticulturae 181:189-193.

Wu QS, Srivastava AK, Zou YN (2013a). AMF-induced tolerance to drought stress in citrus: a review. Scientia Horticulturae 164:77-87.

Wu QS, Xia RX, Zou YN (2008). Improved soil structure and citrus growth after inoculation with three arbscular mycorrhizal fungi under drought stress. European Journal of Soil Biology 44:122-128.

Wu QS, Xia RX, Zou YN, Wang GY (2007). Osmotic solute responses of mycorrhizal citrus (Poncirus trifoliata) seedlings to drought stress. Acta Physiologiae Plantarum 29:543-549.

Wu QS, Zou YN, Huang YM, Li Y, He XH (2013b). Arbuscular mycorrhizal fungi induce sucrose cleavage for carbon supply of arbuscular mycorrhizas in citrus genotypes. Scientia Horticulturae 160:320-325.

Yooyongwech S, Phaukinsang N, Chaum S, Supaibulwatnan K (2013). Arbuscular mycorrhiza improved growth performance in Macadamia tetraphylla $\mathrm{L}$. grown under water deficit stress involves soluble sugar and proline accumulation. Plant Growth Regulation 69:285-293.

Zhang MF, Li ZL (2002). Sucrose-metabolizing enzymes in higher plants. Plant Physiology Communication 38:289-295 (in Chinese with Engish abstract).

ZhangZF, Zhang JC, Huang YQ (2014). Effects of arbuscular mycorrhizal fungi on the drought tolerance of Cyclobalanopsis glauca seedlings under greenhouse conditions. New Forests 45:545-556.

Zou YN, Srivastava AK, NiQD, Wu QS (2015). Disruption of mycorrhizal extraradical mycelium and changes in leaf water status and soil aggregate stability in rootbox-grown trifoliate orange. Frontiers in Microbiology 6:203.

Zou YN, Wu QS, Huang YM, Ni QD, He XH (2013). Mycorrhizalmediated lower proline accumulation in Poncirus trifoliata under water deficit derives from the integration of inhibition of proline synthesis with increase of proline degradation. PLOSONE 8:e80568. 